\title{
Characterization of the Lime Mortars of the Rui Barbosa House Museum in Rio De Janeiro, Brazil
}

\author{
Daniele Pereira da Silva Dalto, Roberto Carlos da Conceição Ribeiro * and \\ Luanna Cavalcanti Rebecchi de Moura
}

Centre of Mineral Technology (CETEM), Av. Pedro Calmon, 900-Ilha da Cidade Universitária, Rio de Janeiro, RJ, 21941-908, Brazil; ddalto@cetem.gov.br (D.P.d.S.D.); lcmoura@cetem.gov.br (L.C.R.d.M.)

* Correspondence: rcarlos@cetem.gov.br; Tel.: +55-21-3865-7264

Received: 18 September 2017; Accepted: 10 January 2018; Published: 3 February 2018

\begin{abstract}
The aim of this research is to characterize the mortars of the Rui Barbosa House Museum, built in 1850, in the city of Rio de Janeiro, Brazil, using X-ray diffraction (XRD), gel-CSH determination, Fourier Transform Infrared spectrometry (FTIR), Wavelength-Dispersive X-ray Fluorescence spectrometry (WDXRF), Thermo gravimetric analysis (TG-DTG), and granulometric analysis. Also, petrographic and physical characteristics such as porosity, water absorption, and apparent density of the mortars were used to identify the raw materials employed in their preparation. Mineralogical associations found are similar (quartz, calcite, kaolinite, microcline, muscovite, and albite) for the majority of samples and only vary in their proportions; the most prominent phases are quartz and calcite. The collected data, indicating that the binder is hydrated lime, lead us to conclude that the analyzed samples are lime mortars, discarding the possibility of cement as the binder material. Two samples, located on the corner of the building, which underwent repairs, present a differentiated behavior, with high levels of dolomite and the presence of pozzolanic material, with greater water absorption and higher density, indicating the use of a different mortar type. In addition, it was verified that the WDXRF and XRD methods are able to determine the trace element composition with comparable precision with respect to the methodological approach proposed by Teutonico (1988). In addition, it has been verified that the major pollutant causing degradation of building are sulfur emitted by the vehicles and saline spray.
\end{abstract}

Keywords: lime mortar; characterization; building wall; façade

\section{Introduction}

Mortar paste is a workable material used to bind masonry blocks together and fill the gaps between them. Typically, historical mortar is a composite, with a binder and an aggregate [1]. Gypsum is one of the oldest binders used by humanity. It was employed in the earliest Egyptian pyramids [2], and recently, it has been reported in most samples of a church founded between the fourth and fifth century at the end of the period when Milan was the capital of the Roman Empire [3]. Mortars with other components such as lime and whale oil have appeared over the years, thus improving the properties of this material [3-6].

The use of lime mortar in Brazil predates the foundation of Salvador City (Bahia) in 1549. Since its first use in Brazil, lime mortar was obtained from lioz stones (limestone) imported from Portugal, where this methodology was commonly used (e.g., in Lisbon) [7]. However, abundant sources of corals were discovered along the Brazilian coastline and shortly served as an excellent substitute, generating high-quality lime [7]. 
Lime was the most common binder for construction, manufacturing, and material coating processes until the beginning of nineteenth century. From this period, with the discovery of Portland cement, this binder has fallen into disuse, compared to some advantages offered by cement, such as rapid hardening, high mechanical strength, and the possibility of being used with steel in the production of structural elements such as slabs, beams, and pillars [7].

The characterization of mortars is very important because it enables a future preparation of restoring mortars with similar properties to those originally used in the construction of historical buildings [8]. Several places in the world have already had their mortars characterized, including those from the Byzantine period, from the sixth to the tenth centuries [8].

Many techniques have been successfully applied in the characterization of historical mortars, including, among others, X-ray diffraction [4,5,9-17], macroscopic observation [18], petrography [6,10,18,19], physical analysis [18], infrared spectroscopy [8,10], chemical analysis [16-18], thermo gravimetric analysis (TG-DTG) [8-10,17,18], mechanical tests [20], and granulometry [8,18].

Ancient mortars may show a high degree of complexity. As an example, we may refer to the bell gable of the church of St. Mary Magdalene, in the Convent of Our Lady of Consolation in Alcalá de Henares (Madrid, Spain) built around 1672 [17]. The physico-chemical characterization of the original mortar used during the construction of the structure was applied as a first step prior to the intervention process. Due to the bad conservation state of the structure, an exhaustive analysis of the damages suffered by the structure was made using, among others, infrared thermography. Mechanical characterization was also necessary to determine the structural stability of the element and the cohesion and resistance of the original materials. The mortar characterization was carried out using complementary analysis techniques, and the conjunction of the results obtained allowed the determination of binder type, possible mortar degradations, and other characteristics, as well as the selection of the most suitable repair materials for the intervention process. The results lead the authors to conclude that a lime mortar was employed, discarding the possibility of cement or gypsum as a binder material. In particular, the binder has been characterized as sub-hydraulic or feebly lime, developed using so-called "hot lime technology" [17].

In this research, the composition and physical properties of mortars taken from Rui Barbosa House Museum was evaluated by X-ray diffraction, petrographic analysis, Raman Spectroscopy, Wavelength-Dispersive X-ray Fluorescence spectrometry, Fourier Transform Infrared spectrometry, thermo gravimetric analysis (TG-DTG), and granulometric and physical analysis to confirm or discard the presence of cement and gypsum as binder materials.

\section{Rui Barbosa House Museum}

Rui Barbosa House Museum (Figure 1) was built in 1850 in the Neoclassical architectural style. It is located in the southern part of the city of Rio de Janeiro in Rio de Janeiro State, Brazil, about $1 \mathrm{~km}$ away from Guanabara Bay $\left(22^{\circ} 56^{\prime} 57.1^{\prime \prime} \mathrm{S} 43^{\circ} 11^{\prime} 13.3^{\prime \prime} \mathrm{W}\right)$ [21]. The Museum has historical and cultural importance to Brazilians: it is part of the Rui Barbosa House Foundation (Ministry of Culture, Brasilia, Brazil), and it was one of the first historic house museums in Brazil. The building was the residence of Ruy Barbosa de Oliveira, who among other duties was a lawyer, a writer, and a politician of great importance to Brazil [22]. 


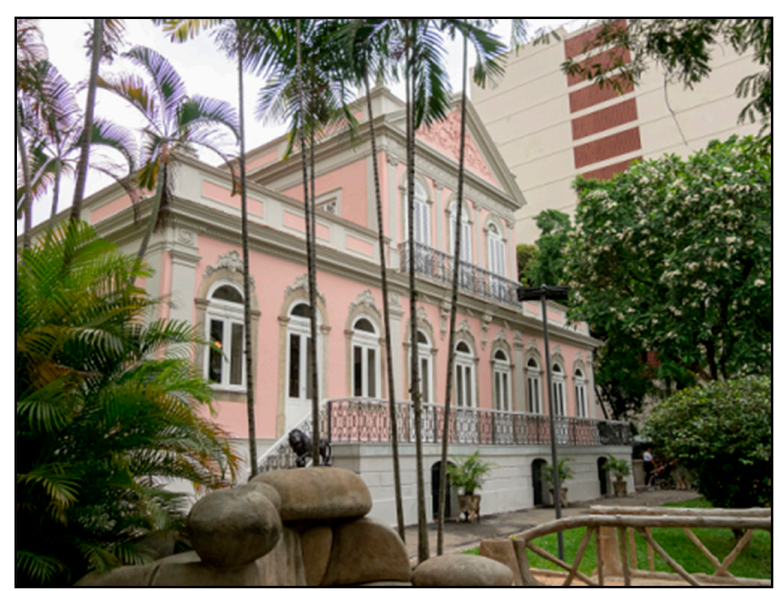

Figure 1. Façade of Rui Barbosa House Museum.

\section{Materials and Methods}

\subsection{Sampling}

Twelve mortar samples were collected from different parts of the building (from the main façade and from the east, north, and west sides of the building) of the Rui Barbosa House Museum (Figure 2):

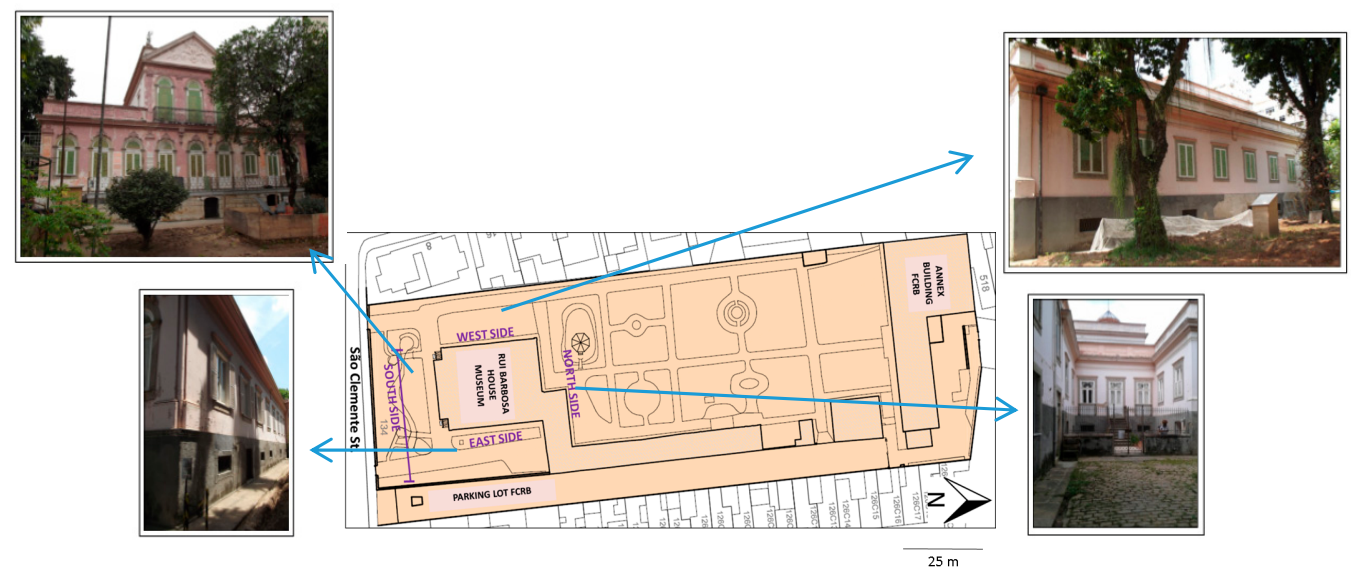

(a)

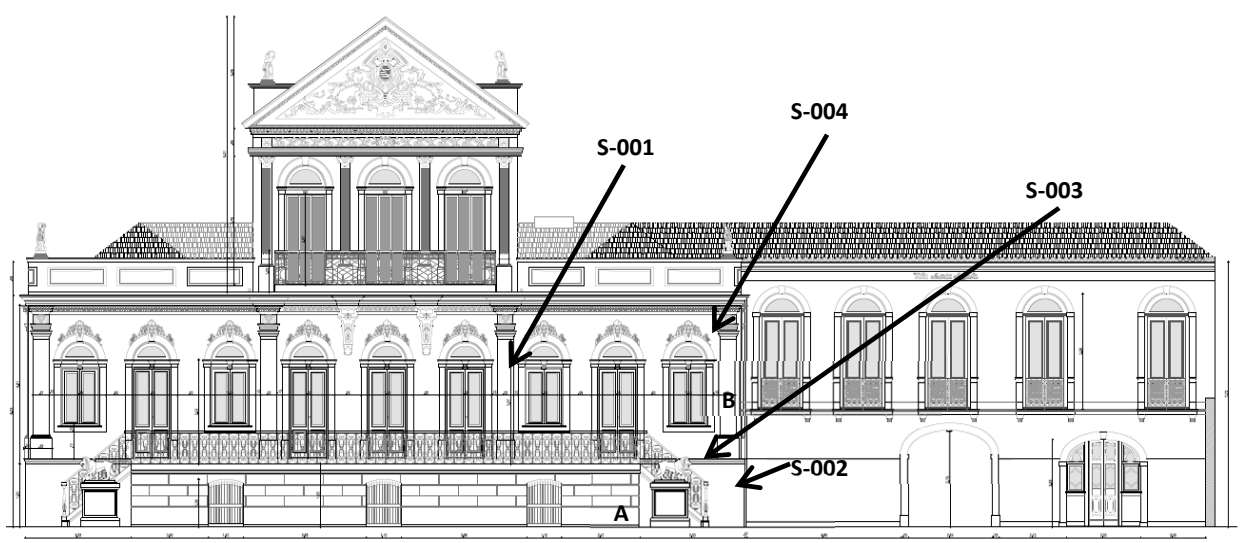

(b)

Figure 2. Cont. 


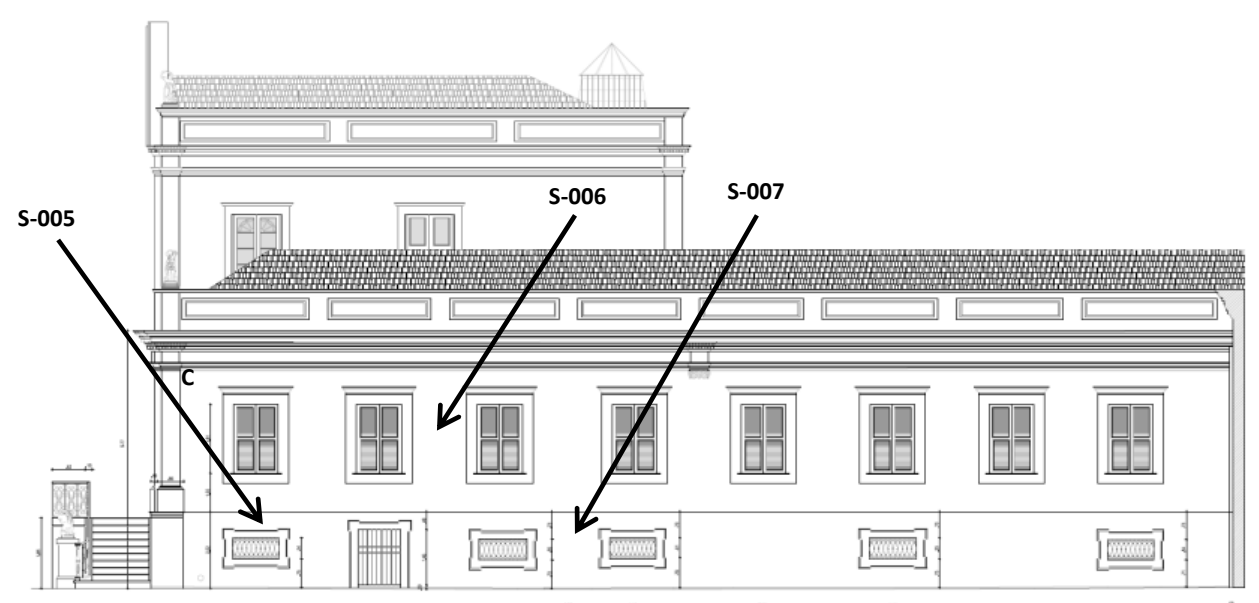

(c)

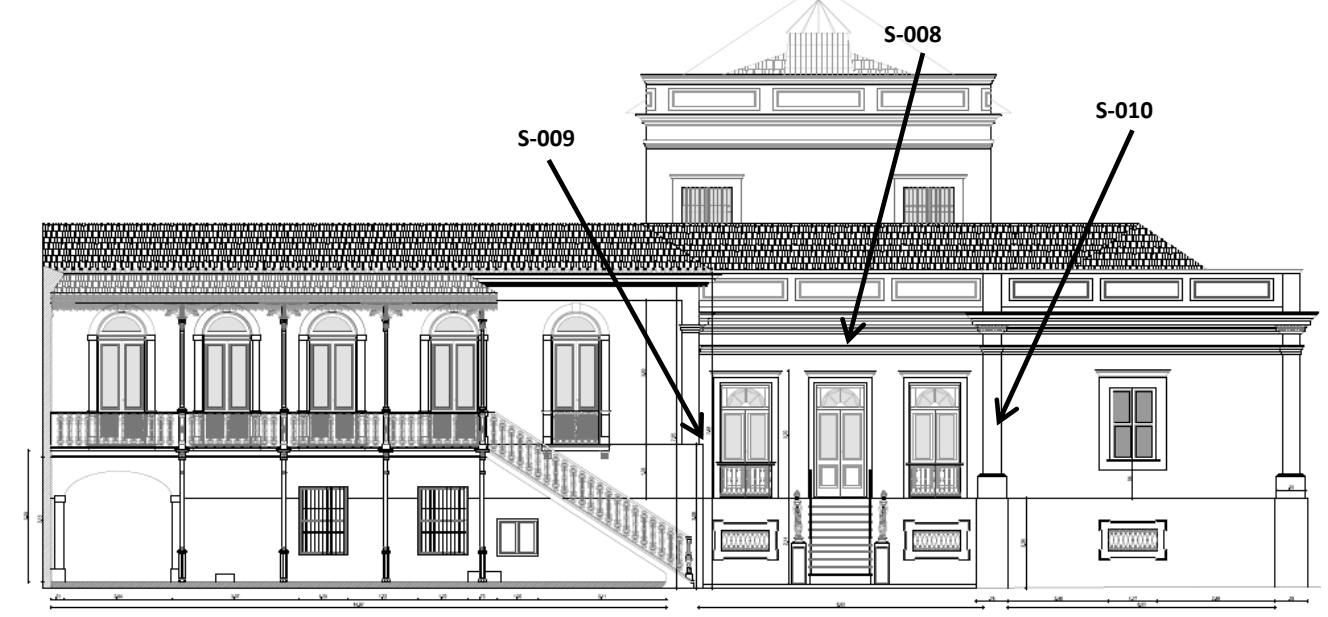

(d)

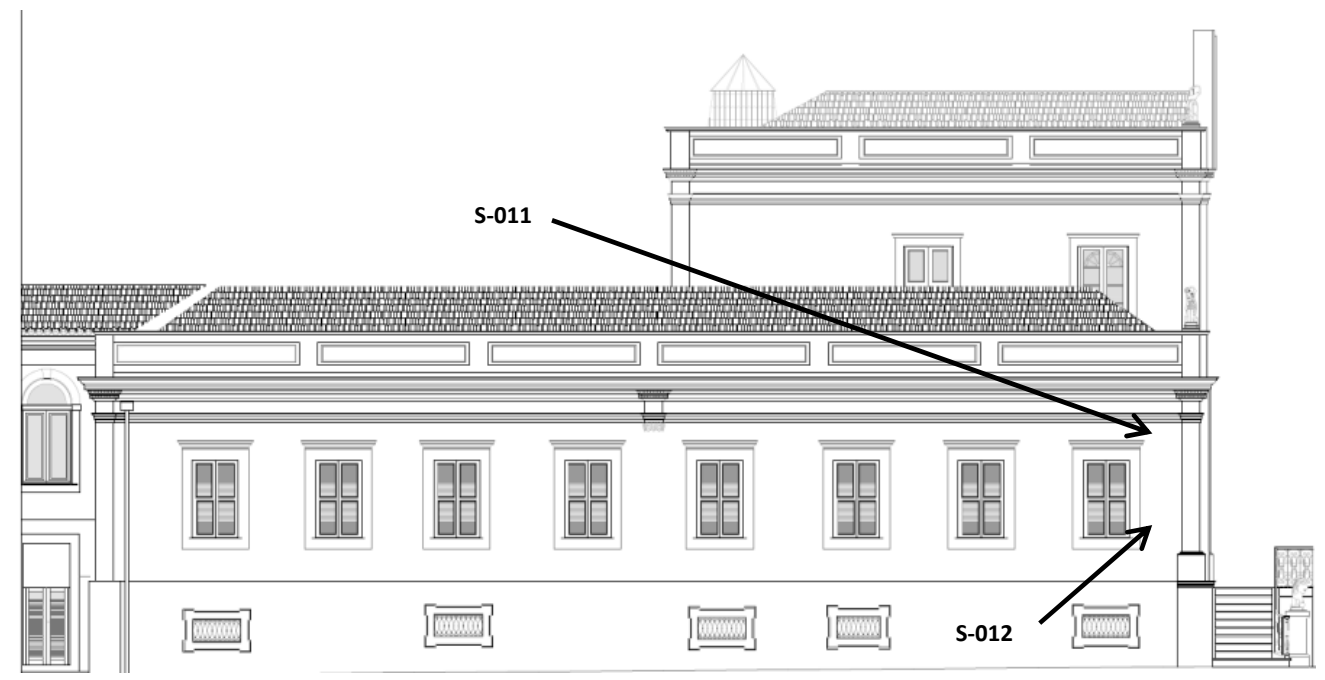

(e)

Figure 2. (a) Plant of Rui Barbosa House Museum; (b) South side, (c) East side, (d) North side, and (e) West side. 
(i) S-001 to S-004: four samples from the South side (façade).

(ii) S-005 to S-007: three from the East side.

(iii) S-008 to S-010: three from the North side.

(iv) S-011 and S-012: two samples from the West side.

In addition, waters used for cleaning three selected points of the façade (from South and East sides, labeled as "A," "B," and " $\mathrm{C}$ " in Figure 2) were collected for analysis (see below).

\subsection{Methods}

The samples were first observed macroscopically for characteristics that can be identified by the naked eye, such as color, texture, shape, and size.

The mortars studied were described using a Schneider magnifying glass (Schneider, Rueil-Malmaison, France) with a Carl Zeiss lens (Carl Zeiss, Jena, Germany), zoomed in from 6.5× to $60 \times$, and fluorescent light. The Raman analyses were carried out, to support the observation, using a BWTEK Raman device (Raman PRO, Newark, DE, USA). The equipment covers a spectral range in Raman displacement of $150-3000 \mathrm{~cm}^{-1}$, with a spectral resolution of $5 \mathrm{~cm}^{-1}$. Spectra were acquired using commercial software provided by B\&W TEK. Some samples were separated for physical analysis; thin sections were also prepared for petrographic analysis by vacuum impregnation using an epoxy resin. The remainder of each sample was manually ground using an agate mortar and pestle, sieved up to $105 \mu \mathrm{m}$, and characterized using X-ray Powder Diffraction (XRPD), CSH-gel, Fourier Transform Infrared Spectrometry (FTIR, Beaconsfield Bucks, UK), and Wavelength-Dispersive X-ray Fluorescence Spectrometry Panalytical WDS-1 spectrometer (WDXRF) (Axios Max, Almelo, The Netherland). X-ray diffraction spectra were obtained by a Bruker D4-Endeavor instrument $(40 \mathrm{kV}$, $40 \mathrm{~mA}$ ) (D8 Endeavor, Ettlinger, Germany) with a CoK $\alpha$ wavelength, from $10^{\circ}$ to $100^{\circ}$ in $2 \theta$, step size of $0.02^{\circ}$ and $3.6 \mathrm{~s} /$ step scan.

Amorphous phases cannot be detected directly by X-ray diffraction analysis. However, by using a defined quantity of crystalline standard material it is possible to determine the ratio of crystalline material in the sample to the crystalline standard and thus calculate the content of amorphous material in the sample. The methodology described in Walentaa and Füllmannb (2004) [23] was used, adding about $17 \%$ (by weight) of fluorite to each sample.

For application of the Fourier transform infrared spectrometry (FTIR) to the qualitative identification of compounds present in the mortars, such as salts and organic composites, a Perkin Elmer Spectrum 400 was employed. The pellets, about $13 \mathrm{~mm}$ in diameters, contained approximately $2.0 \%$ of the sample; they were well mixed with $300 \mathrm{mg}$ of potassium bromide.

Thin sections were observed through a binocular transmitted light, Carl Zeiss microscope, equipped with objectives ranging in magnification from $2.5 \times$ to $60 \times$.

The samples for WDXRF analysis were dried in oven at $100{ }^{\circ} \mathrm{C}$; then about $7 \mathrm{~g}$ of each sample were pressed into uniform pellets (20 $\mathrm{mm}$ in diameter) using a Vaneox automatic press machine under 20 tons of pressure with a standing time of $30 \mathrm{~s}$, using boric acid as base. All the measurements were carried out on an AXIOS Panalytical WDS-1 spectrometer. The loss on ignition (LOI) was detected using Lecco TGA-701 equipment (TGA 701, St. Joseph, MI, USA), with a rate of $10^{\circ} \mathrm{C} / \mathrm{min}^{-1}$ in the range $25-110^{\circ} \mathrm{C}$ and $40{ }^{\circ} \mathrm{C} / \mathrm{min}^{-1}$ from 110 to $1000{ }^{\circ} \mathrm{C}$.

Apparent density, porosity, and water absorption were measured at atmospheric pressure by a Marte AD2000 hydrostastic balance (water-saturated samples), while the dried samples were analyzed by means of a Shimadzu AY220 balance.

Selected portions of the facade (samples A, B, C: see Figure 2) were cleaned with distilled water with the aid of a brush. Water used for cleaning operations was then collected and analyzed by atomic absorption spectrometry Varian Spectra AA 55B (Varian Australia PTY, Victoria, Australia). 


\section{Results and Discussion}

\subsection{Macroscopic Description, Observation, and Raman Spectroscopy}

The mortar samples analyzed present similar aspects (Figure 3a). They are all composed of a fine, amorphous matrix that is light gray to light beige, containing relatively large crystals visible to the naked eye. Among them, milky to colorless quartz is dominant, with various shapes, but mainly elongated. Another phase is clearly observable: spherical grains with rounded edges and slightly pinkish grains of K-feldspars with rounded edges are also visible. Voids occur in all samples. In addition, there are friable, whitish grains with various forms, usually submillimetric. Finally, relatively large grains of opaque phases may also be present in the mortar samples.

It is noteworthy that in the hand samples S-005 and S-008, two additional layers (besides the mortar) were preserved: the pictorial layer and a layer of running mass, predominantly composed of a very fine matrix with few quartz crystals and the friable whitish grains.

Sample S-006 has no pictorial layer. Although this mortar is very similar to the others, being composed of the same thin, light gray matrix and the grains types, we noticed more abundant porosity than the others and a less cohesive aspect.

Based on both cohesion and color of the binders (see Figure 3), the analyzed samples can be divided into two groups. The first one includes the samples S-002, S-003, S-005, S-006, and S-012, characterized by a more cohesive matrix with aggregates that are well-adhered and massive. The binder has light color (beige to grey), and evenly distributed lime lumps are abundant, as confirmed by optical microscopy. A mineral with ochre color was observed to be dispersed in the binder, identified as plagioclase by Raman analysis. The occurrence of staining (evidenced by the presence of iron oxyhydroxides) was seen in all samples, usually in close proximity to plagioclase.

The second group is composed by samples S-007, S-008, S-009, and S-011, where the binders are brownish and present a powdery aspect, more evidently in S-007. The binder is dark in color (brown); the occurrence of grains of sand was noticed.

In sample S-012 (Figure 3b), the presence of a wood piece was observed. During the sampling, the detachment of the ink layer from the walls of the building was observed in a few areas, presumably due to the strong action of water, since humidity is high, but no other sign of either chemical or biological degradation was observed.

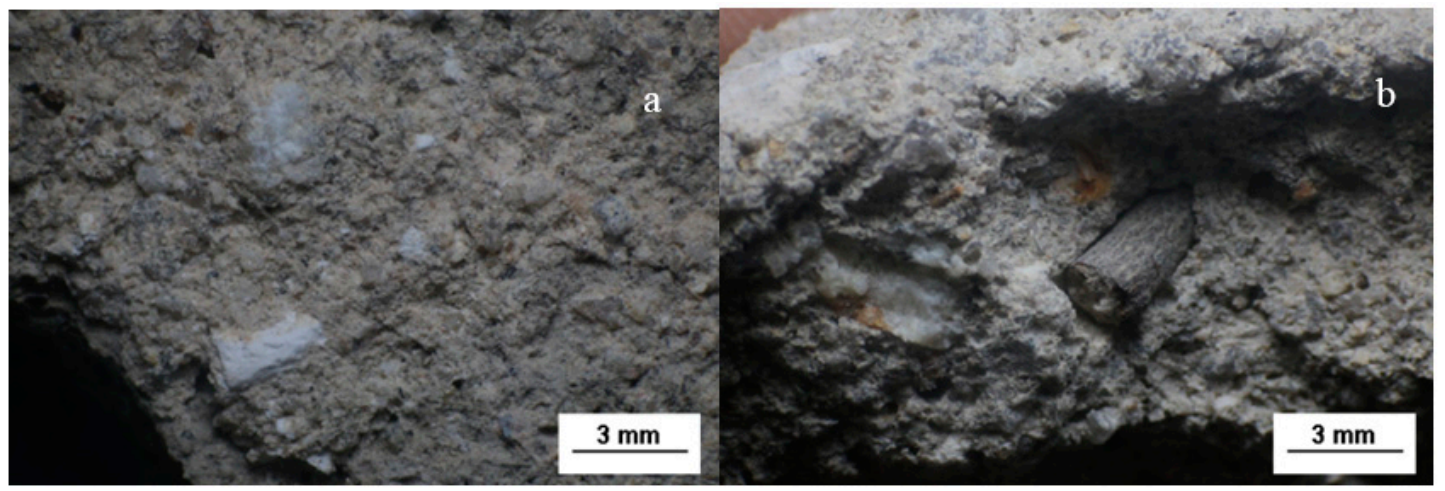

Figure 3. (a) General aspect of the mortars (S-007); (b) Presence of wood in the mortar (S-012).

Differently from all other samples, S-001 has a light pink to pale yellow binder. The aggregate grains have small grain size; quartz crystals are still abundant, with angular shapes, but are smaller in size and in minor quantity when compared to the other samples. The presence of shell pieces is more frequent. This mortar sample is more coherent.

Sample S-002, Figure 4a, shows a white and pink matrix. The grains immersed in the matrix are mostly of quartz, and in lesser amounts, muscovite, oxides, and feldspars. 
Quartz crystals present anhedral habit and translucent or gray color. The quartz grains have a maximum length of $2 \mathrm{~mm}$. In some quartz grains, inclusions of oxides or red stains that are probably the product of the oxidation of the oxides were observed. Muscovite occurs as crystals unevenly disseminated with subhedral habit and micaceous glow and approximately $0.2 \mathrm{~mm}$ in length. The oxides are rounded and have a black color. Sometimes, these minerals are oxidized, so it is only possible to observe small red dots in the sample. The oxides are approximately $0.5 \mathrm{~mm}$ in length. The feldspar crystals have a pink color and are mostly anhedral. It is possible to observe pores on the surface of the sample, mainly in places where grains of sand are abundant.

Sample S-004, Figure $4 \mathrm{~b}$, shows a white matrix (lime), crystals of quartz, and a grain size ranging from clay to sand. The grains immersed in the matrix are mainly quartz, and feldspar, biotite, oxides, rock fragments, vegetable roots, and carbonaceous material (similar to coal) also appear in smaller amounts. The quartz presents round anhedral habit, or prismatic subhedral. The crystals' length can be up to $3 \mathrm{~mm}$. The feldspars are sparse, approximately $1 \mathrm{~mm}$ in length, and pink in color. The oxides are black in color, rounded, and approximately $0.1 \mathrm{~mm}$ in length. Fragments of roots of vegetables with $3 \mathrm{~mm}$ of length, and black material of low hardness (carbonaceous material) can also be observed. Carbonaceous material occurs with rounded shape and up to $4 \mathrm{~mm}$ in length.

In sample S-009, there are rounded masses of lime with maximum length varying between 1 and $4 \mathrm{~mm}$ (Figure 4c).

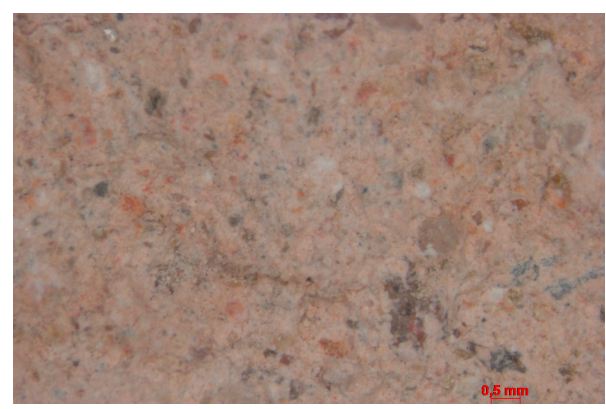

(a)

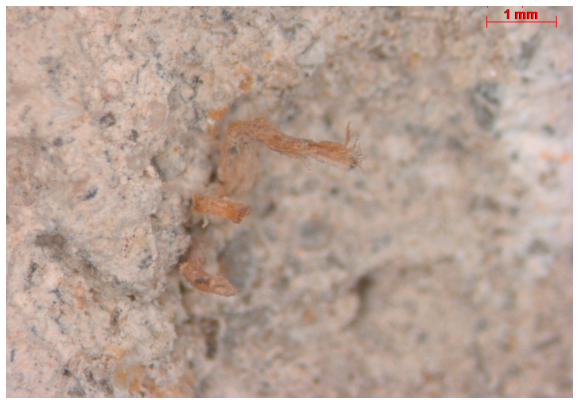

(b)

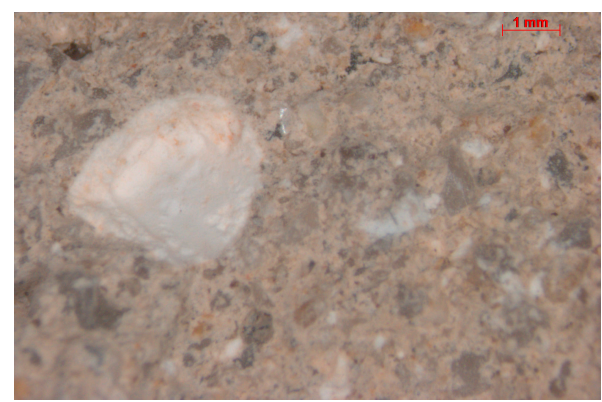

(c)

Figure 4. Macroscopic aspect of mortar samples S-002 (a), S-004 (b), and S-009 (c). 


\subsection{Mineralogical and Petrographic Characterization}

\subsubsection{Mineralogical Analysis}

The mineralogical analysis by XRPD (Table 1) indicated that calcite and quartz are the main components of the binder and aggregate, respectively. Phyllosilicates (kaolinite and muscovite) and K-feldspars (microcline) are present in smaller amounts. Traces of albite were found in most of the samples analyzed. Ettringite, gypsum, and portlandite have not been found in the samples. Therefore, the mortars of Rui Barbosa House Museum are composed mainly by siliceous aggregates and calcitic lime binder.

Table 1. Mineralogical composition of the mortars assessed by X-ray Powder Diffraction (XRPD).

\begin{tabular}{cccccccc}
\hline Sample & Quartz & Calcite & Kaolinite & Microcline & Muscovite & Albite & Dolomite \\
\hline S-001 & +++ & +++ & $\mathrm{t}$ & + & + & $\mathrm{t}$ & $\mathrm{t}$ \\
$\mathrm{S}-002$ & +++ & ++ & +++ & ++ & + & $\mathrm{t}$ & $\mathrm{t}$ \\
$\mathrm{S}-003$ & +++ & ++ & ++ & ++ & + & $\mathrm{t}$ & $\mathrm{t}$ \\
$\mathrm{S}-004$ & +++ & + & + & + & + & $\mathrm{t}$ & $\mathrm{t}$ \\
$\mathrm{S}-005$ & + & +++ & ++ & + & + & + & +++ \\
S-006 & +++ & ++ & ++ & + & + & $\mathrm{t}$ & $\mathrm{t}$ \\
$\mathrm{S}-007$ & +++ & ++ & + & + & + & $\mathrm{t}$ & $\mathrm{t}$ \\
$\mathrm{S}-008$ & +++ & ++ & + & + & ++ & $\mathrm{t}$ & $\mathrm{t}$ \\
$\mathrm{S}-009$ & +++ & + & - & $\mathrm{t}$ & $\mathrm{t}$ & - & $\mathrm{t}$ \\
$\mathrm{S}-010$ & +++ & ++ & - & $\mathrm{t}$ & + & $\mathrm{t}$ & $\mathrm{t}$ \\
$\mathrm{S}-011$ & +++ & + & - & - & $\mathrm{t}$ & $\mathrm{t}$ & $\mathrm{t}$ \\
$\mathrm{S}-012$ & +++ & + & $\mathrm{t}$ & $\mathrm{t}$ & + & $\mathrm{t}$ & $\mathrm{t}$ \\
\hline
\end{tabular}

Notation: +++ (abundant); ++ (present); + (small amount); t (traces); - (undetected).

Sample S-002 and S-005 present a very different mineralogical composition with respect to the other mortar samples. The first (S-002) shows high contents of lime and pozzolanic material, evidenced by the presence of kaolinite. Sample S-005 presents abundant dolomite and calcite and little amounts of sand.

The sampling point of sample S-005 is a place of greater visitor circulation and, consequently, potentially subjected to greater damage: as a consequence, the original mortar was probably replaced by mortars whose composition did not follow the pattern of the other mortars of the house.

\subsubsection{Petrographic Analysis}

The petrographic analysis by optical microscope observations helped us to identify the aggregate grains, their morphology, alteration state, and the mortar texture. The aggregates are mainly composed of polycrystalline quartz and K-feldspars.

The pores observed in mortars have irregular shapes and sizes. Sample S-001 is a mortar with a microcrystalline binder (Figure 5a), mostly beige or pink in color, sometimes dark brown (Figure 5b). Some rounded holes can be seen, which can suggest empty spaces probably produced during the lamination process. The aggregate presents mostly millimetric, angular fragments of quartz that are well dispersed in the binder. There are feldspars as well, together with some very small crystals of muscovite and biotite.

Ochre staining can be seen around some minerals (Figure 5c). An important aspect of sample S-001 compared to all the others is the presence of shell fragments (Figure $5 \mathrm{~d}$ ), which are different in shapes and sizes. 

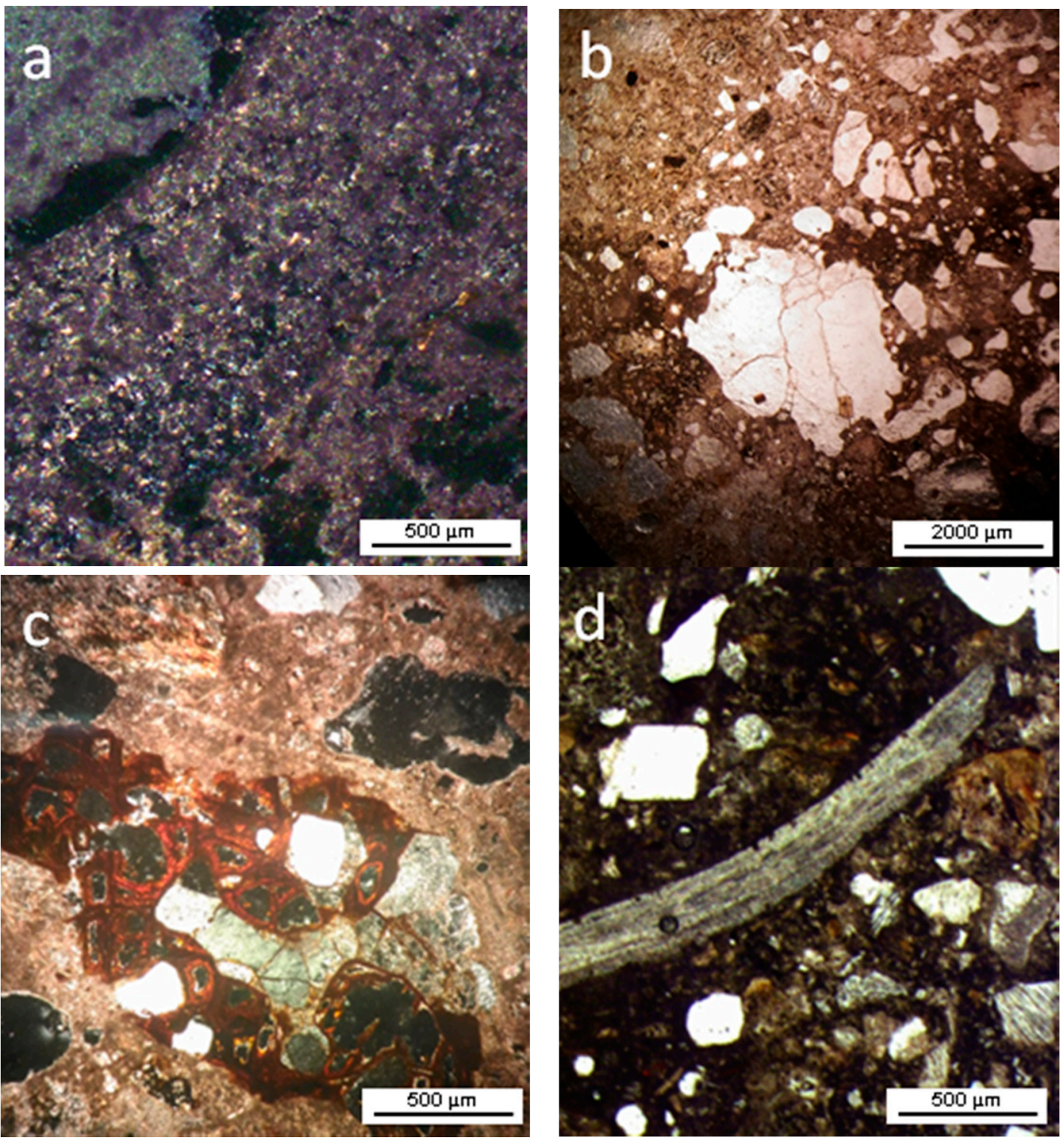

Figure 5. Microphotograph (transmitted light) of the S-001 mortar sample: (a) very thin matrix (10×, \#), (b) matrix with two colors $(2.5 \times, / /)$, (c) ochre staining $(10 \times, / /)$, and (d) shell fragments $(10 \times, / /)$. \#: parallel and //: perpendicular.

The other mortars are similar; they all have brown binder matrix and aggregate grains of angular quartz, feldspars, and some biotites (Figure 6a). In sample S-002 (Figure 6d), it is possible to observe some carbonate grains (Figure 6b), an irregular porosity (Figure 6c), and ochre staining. In sample S-007, the porosity appears to be even higher (Figure 6e,f).

The sample S-004 (Figure 7) shows a very fine mortar matrix and brownish coloration in polarized light. Among various mineral phases, there is a predominance of spherical, angular to subangular grains-less than $0.5 \mathrm{~mm}$ in length—of K-feldspar (microcline) showing the typical cross-hatched twin pattern (Figure 7, red dotted circle), sub millimetric, rounded habit, sometimes with altered edges. Some plagioclases were also observed. The presence of heavily rounded calcites, with altered edges, and muscovite fragments, slightly larger than those present in other samples (for example, S-006), were also found. It is noteworthy that garnet was identified in the thin section of sample S-005. 

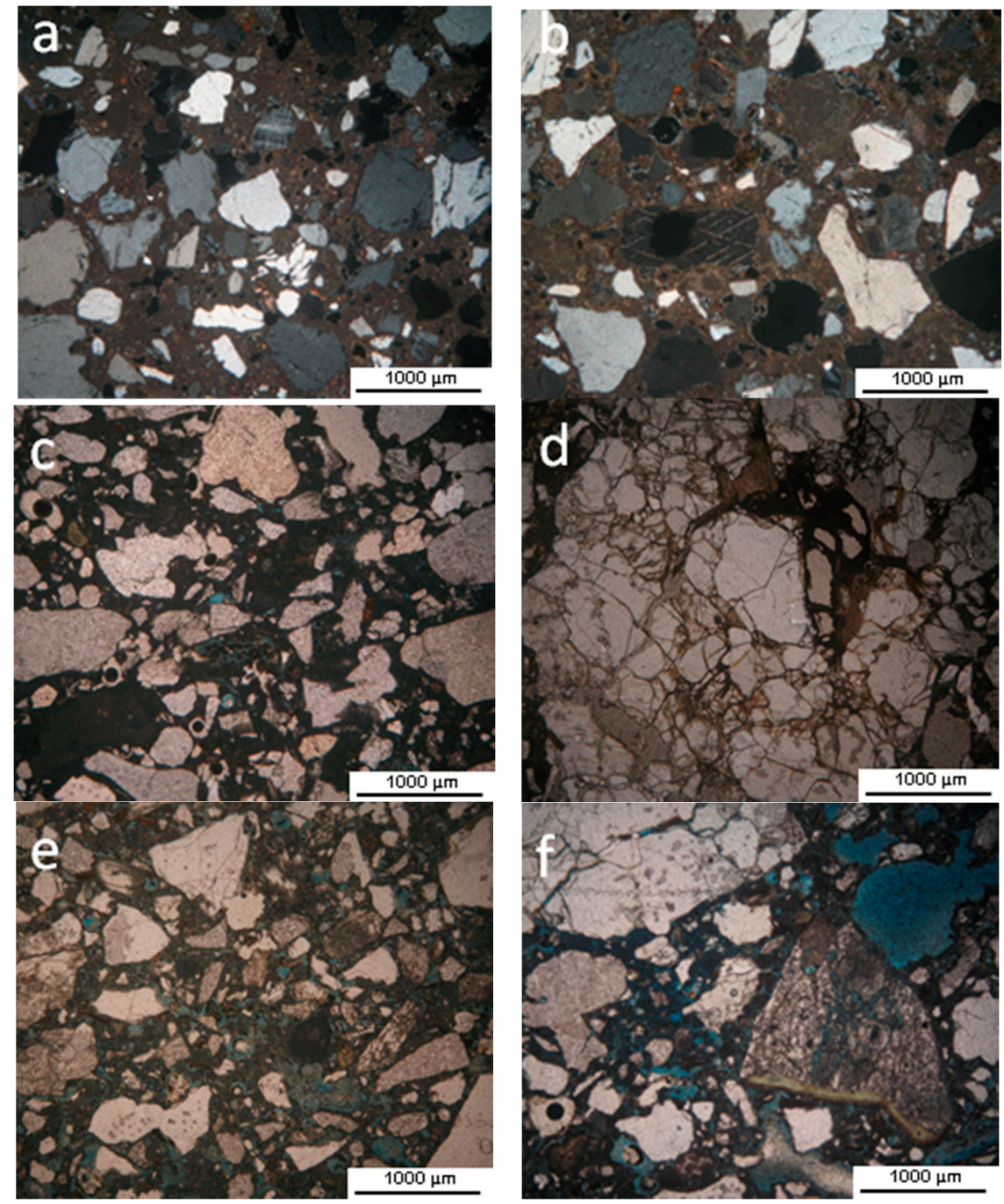

Figure 6. Petrographic observation of samples. (a) general aspect of the mortar showing the presence of polycrystalline quartz grains, feldspars and small fragments of carbonates (sample S-005, 2.5 $\times$,\#); (b) carbonate fragment (sample S-002, 5.0 $\times$,\#); (c) irregular porosity (sample S-002, 2.5 $\times$, / /); (d) ochre staining (sample S-002, 2.5 × / /); (e) sample with high porosity (sample S-007, 2.5 $\times, / /$ ); (f) altered K-feldspar (sample S-007, 5.0×, //). \#: parallel and //: perpendicular.

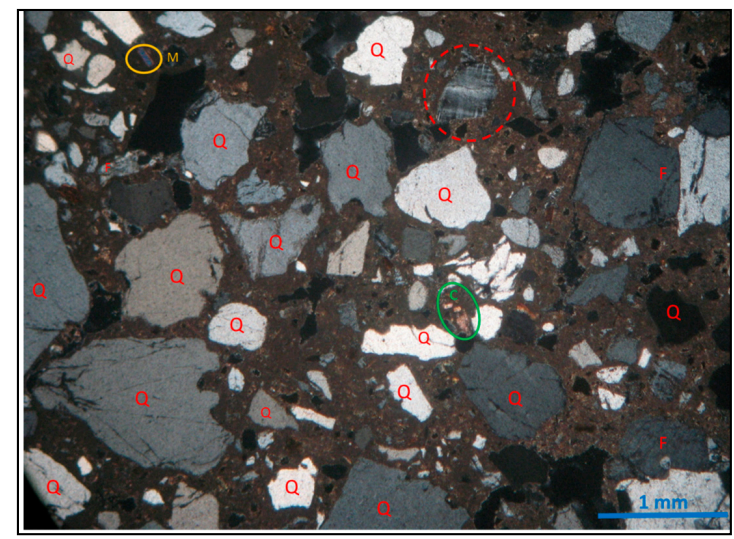

Figure 7. Micrography of sample S-004 (2.5×). Mineral abbreviations: Q: quartz; C: calcite; F: feldspar; M: muscovite. The red dotted circle encloses a crystal of microcline (K-feldspar). 
It should be mentioned that feldspars, often partially altered to clay minerals, are ubiquitous (see Figure 8). Therefore, petrographic analysis confirms our interpretation of macroscopic features shown by whitish friable spots, well distinguishable from the mortar matrix. By means of dyeing, several empty spaces were highlighted, some of which appear to be due to loss of materials during sample preparation.

The S-005 sample (Figure 8) stands out in this respect among all the others because it has a greater amount of voids, part of which may also be original, i.e., formed because the mortar has not been well mixed during preparation.

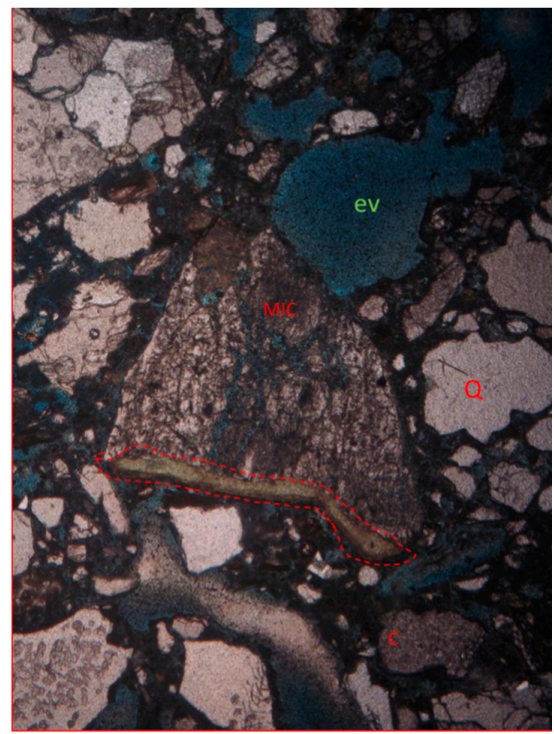

Figure 8. Micrograph of sample S-005 $(2.5 \times)$. Q: quartz; C: calcite; mic: microcline (K-feldspar); ev: voids.

To determine the relative abundances (\%) of the mortars' components, the methodology described in Walentaa and Füllmannb (2004) [23] was used. The mineralogical composition of mortars (Table 2) may be ascribed to the use of sand and lime for their preparation. However, samples S-002 and S-005 exhibit some different features. Sample S-002 contains about $40 \%$ of calcium silicate hydrate (CSH), indicating that it is a mortar made with lime and pozzolanic material. This mortar presents a greater quantity of calcined clay minerals, and it is more spongy and denser than the others.

The sample S-005 has a higher dolomite content and a lower amount of silica, indicating that it is a mortar with a greater aggregation power, since the dolomite is more adhesive.

Table 2. Mineralogical composition (\%).

\begin{tabular}{cccccc}
\hline Phase Name & S-001 & S-002 & S-005 & S-008 & S-012 \\
\hline Calcite & 66.6 & 27.9 & 26.7 & 15.4 & 72.2 \\
Quartz & 12.6 & 15.3 & 1.6 & 43.7 & 11.5 \\
Microcline & 2.7 & 10.4 & 6.1 & 12.6 & 2.3 \\
Gypsum & 0.9 & 1.1 & 0.8 & 0.0 & 0.0 \\
Kaolinite & 0.0 & 4.7 & 1.2 & 2.7 & 0.0 \\
Muscovite & 0.0 & 1.5 & 1.1 & 1.3 & 0.3 \\
Pyrophyllite & 0.0 & 0.0 & 1.0 & 0.0 & 0.0 \\
Hornblende magnesium iron & 0.0 & 0.0 & 2.6 & 0.0 & 0.0 \\
Dolomite & 0.0 & 0.0 & 25.1 & 0.0 & 0.0 \\
Talc & 0.0 & 0.0 & 3.3 & 0.0 & 0.0 \\
Barite & 0.0 & 0.0 & 4.7 & 0.0 & 0.0 \\
Pseudorutile & 0.0 & 0.0 & 3.8 & 0.0 & 0.0 \\
Amorphous (CSH) & 17.2 & 39.0 & 22.0 & 24.3 & 13.7 \\
Total & 100.0 & 100.0 & 100.0 & 100.0 & 100.0 \\
\hline
\end{tabular}


Figure 9 shows the granulometric distribution histogram of the collected mortar samples. All samples showed very similar granulometry. Most particles have an equivalent diameter of 0.6 to $2.0 \mathrm{~mm}$, corresponding to the characteristic granulometry of coarse to medium/fine sand, although minor amounts of silty/clayey portions may be present.

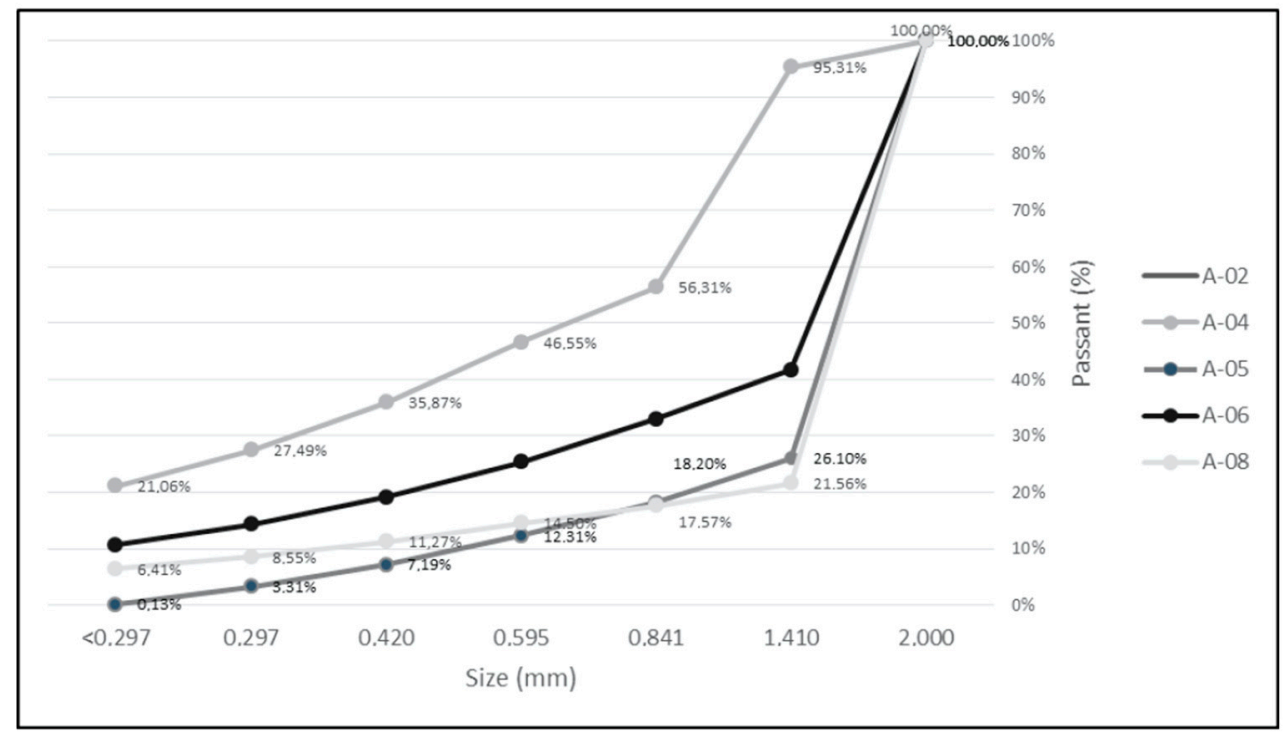

Figure 9. Granulometric distribution (\%).

\subsection{Chemical Characterization}

\subsubsection{WDXRF Analysis}

$\mathrm{SiO}_{2}(33.20$ to $70.00 \mathrm{wt} \%)$ and $\mathrm{CaO}(6.10$ to $29.20 \mathrm{wt} \%)$ are the most abundant components, as revealed by WDXRF analysis (Table 3). $\mathrm{SiO}_{2} / \mathrm{CaO}$ ratio (wt \%) ranges from 1 (sample S-001) to 4 (samples S-007, S-009, and S-011). The only exceptions are samples S-008 and S-010, both from the North side, where the ratio is higher than 8.0 due to the much lower lime content. The high content of $\mathrm{SiO}_{2}$, in all samples, is in accordance with the common abundance of quartz, although at places, it may be explained also by the use of natural hydraulic lime (for example, lime coming from marls or impure argillaceous limestones). Sample S-002 presents high silica contents, possibly associated with the abundance of kaolinite.

Table 3. Chemical composition and loss on ignition (wt \%) by WDXRF analysis of mortars.

\begin{tabular}{cccccccccccc}
\hline Sample & Side & $\mathrm{SiO}_{2}$ & $\mathrm{TiO}_{2}$ & $\mathrm{Al}_{\mathbf{2}} \mathbf{O}_{\mathbf{3}}$ & $\mathrm{Fe}_{\mathbf{2}} \mathbf{O}_{\mathbf{3}}$ & $\mathbf{M g O}$ & $\mathbf{C a O}$ & $\mathbf{N a}_{2} \mathbf{O}$ & $\mathbf{K}_{\mathbf{2}} \mathbf{O}$ & $\mathbf{S O}_{3}$ & LOI \\
\hline S-001 & South & 33.20 & 0.29 & 10.70 & 2.50 & 0.80 & 29.20 & 0.64 & 1.80 & 0.87 & 19.70 \\
S-002 & South & 58.40 & 0.13 & 7.60 & 1.20 & 0.43 & 18.80 & 0.69 & 1.80 & 0.32 & 10.30 \\
S-003 & South & 56.00 & 0.14 & 7.70 & 1.50 & 0.42 & 19.60 & 0.92 & 2.00 & 0.76 & 10.60 \\
S-004 & South & 55.40 & 0.13 & 7.56 & 1.40 & 0.55 & 18.90 & 0.73 & 2.00 & 0.51 & 10.40 \\
S-005 & East & 1.43 & 0.21 & 6.70 & 1.82 & 29.44 & 28.8 & 0.44 & 1.67 & 0.61 & 28.88 \\
S-006 & East & 61.00 & 0.12 & 4.90 & 0.78 & 0.50 & 19.50 & 0.79 & 1.10 & 0.85 & 10.20 \\
S-007 & East & 61.00 & 0.15 & 8.10 & 1.30 & 0.40 & 16.10 & 0.97 & 1.90 & 0.41 & 9.30 \\
S-008 & North & 64.80 & 0.24 & 15.30 & 1.70 & 0.59 & 6.10 & 1.90 & 3.60 & 0.24 & 5.10 \\
S-009 & North & 70.00 & $<0.10$ & 1.80 & 0.42 & 0.48 & 16.00 & 0.19 & 0.30 & 0.33 & 10.10 \\
S-010 & North & 69.30 & 0.36 & 9.30 & 1.60 & 1.30 & 8.60 & 0.94 & 2.00 & 0.65 & 5.40 \\
S-011 & West & 60.30 & 0.11 & 6.90 & 1.10 & 0.36 & 16.10 & 0.96 & 1.60 & 0.44 & 11.70 \\
S-012 & West & 70.00 & 0.11 & 6.60 & 1.10 & 0.32 & 12.10 & 0.82 & 1.60 & 0.32 & 7.00 \\
\hline
\end{tabular}


$\mathrm{Na}_{2} \mathrm{O}$ is constantly low $(<2 \%) . \mathrm{MgO}$ shows the same trend, except for sample S-005, where the high magnesium contents are in accordance with the abundance of dolomite. The average values of aluminum oxide $\left(\mathrm{Al}_{2} \mathrm{O}_{3}\right)$ is around $7 \%$; only sample S-009 presented less than $4 \% \mathrm{Al}_{2} \mathrm{O}_{3}$. Titanium oxide $\left(\mathrm{TiO}_{2}\right)$ is constantly below $0.4 \%$. The $\mathrm{SO}_{3}$ content is low $(<1 \%)$ in all the samples.

The WDXRF results confirmed $X$-ray diffraction results as follows:

(i) All samples contain high percentages of both quartz and calcite;

(ii) The high silica content can be linked to the percentage of quartz present in mortars and can be influenced also by the use of natural hydraulic lime. For this reason, future studies are needed to determine the type of binder from Rui Barbosa House Museum;

(iii) There are comparatively lower amounts (often only traces) of kaolinite, microcline, muscovite, and albite.

\subsubsection{FTIR Analysis}

FTIR spectra of samples taken from all the four sides of the Museum (reported in Figure 10) are very similar. The presence of bands of calcium carbonate $\left(1430,873\right.$ and $712 \mathrm{~cm}^{-1}$ ) are in accordance with the LOI values of Table 3. The characteristic silicate band ( $\mathrm{Si}-\mathrm{O}-\mathrm{Si}$ ) appears close to $1030 \mathrm{~cm}^{-1}[24,25]$. It is worth mentioning that these analyses confirmed X-ray diffraction and X-ray fluorescence results. In fact, the four samples clearly show the presence of quartz $(1874,1072,794$, $\left.695 \mathrm{~cm}^{-1}\right)$ and calcite $\left(1796,1430,874,713 \mathrm{~cm}^{-1}\right)$ and contain small amounts of kaolinite $\left(535 \mathrm{~cm}^{-1}\right)$, albite $\left(778 \mathrm{~cm}^{-1}\right)$, and microcline $\left(648 \mathrm{~cm}^{-1}\right)$ [26-29]. Organic compounds and hydrate salts were not detected.

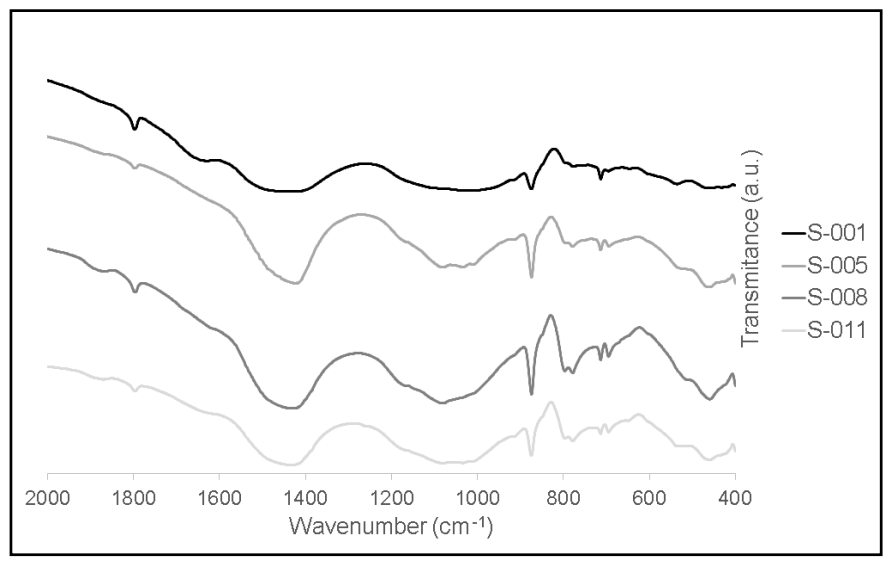

Figure 10. FTIR spectra's of samples. S-001 (South), S-005 (East), S-008 (North), and S-011 (West).

\subsection{Physical Analysis of the Mortars}

Physical properties of the analyzed mortars like porosity and water absorption at atmospheric pressure are highly dependent on the amount of voids (Figure 11). The porosity of samples varies between $14 \%$ and $33 \%$ and the water absorption between $7 \%$ and $21 \%$ by weight. Mortar samples taken from the South and West sides give very similar results after these physical analyses. Samples from the East and North sides have higher values for total porosity and water absorption.

However, sample S-002 (South side) presents much higher water absorption (35\%) than the others, probably due to the presence of kaolinite and its pozzolanic composition. 

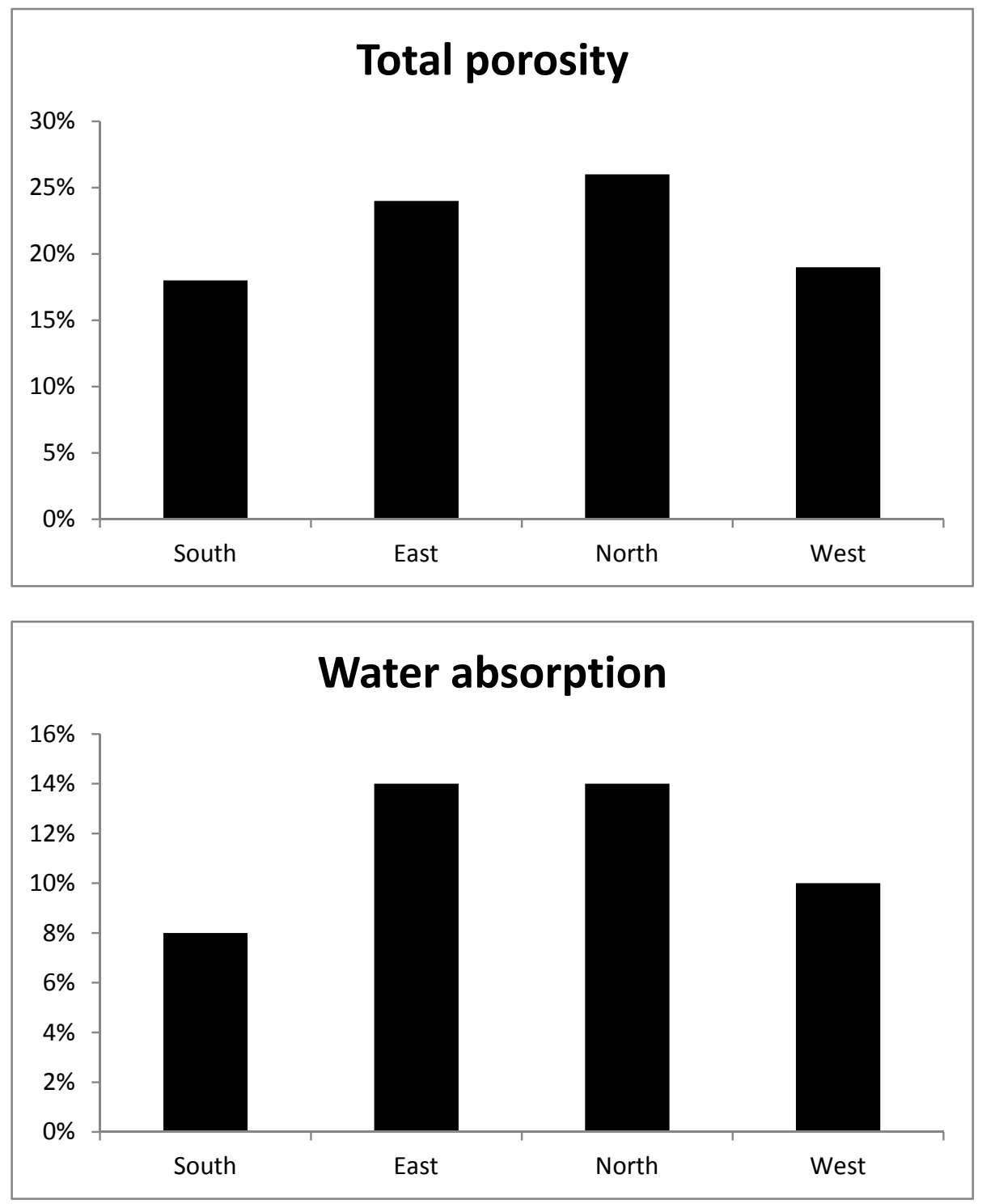

Figure 11. Total porosity and water absorption at atmospheric pressure with standard deviation of the samples. S-001 (South), S-005 (East), S-008 (North) and S-011 (West).

Figure 12 shows the apparent density of the samples S-001 (South), S-005 (East), S-008 (North) and S-011 (West). The average values of measured dry and water-saturated apparent density are of, respectively, $1761 \mathrm{~kg} \cdot \mathrm{m}^{-3}$ and $1993 \mathrm{~kg} \cdot \mathrm{m}^{-3}$, respectively. All samples from the Museum presented apparent density values compatible with those reported in the literature [18]. It is important to mention that physical properties can be influenced by many factors, such as typology of aggregate, typology of binder, aggregate/binder ratio, degradation phenomena, and weathering. 


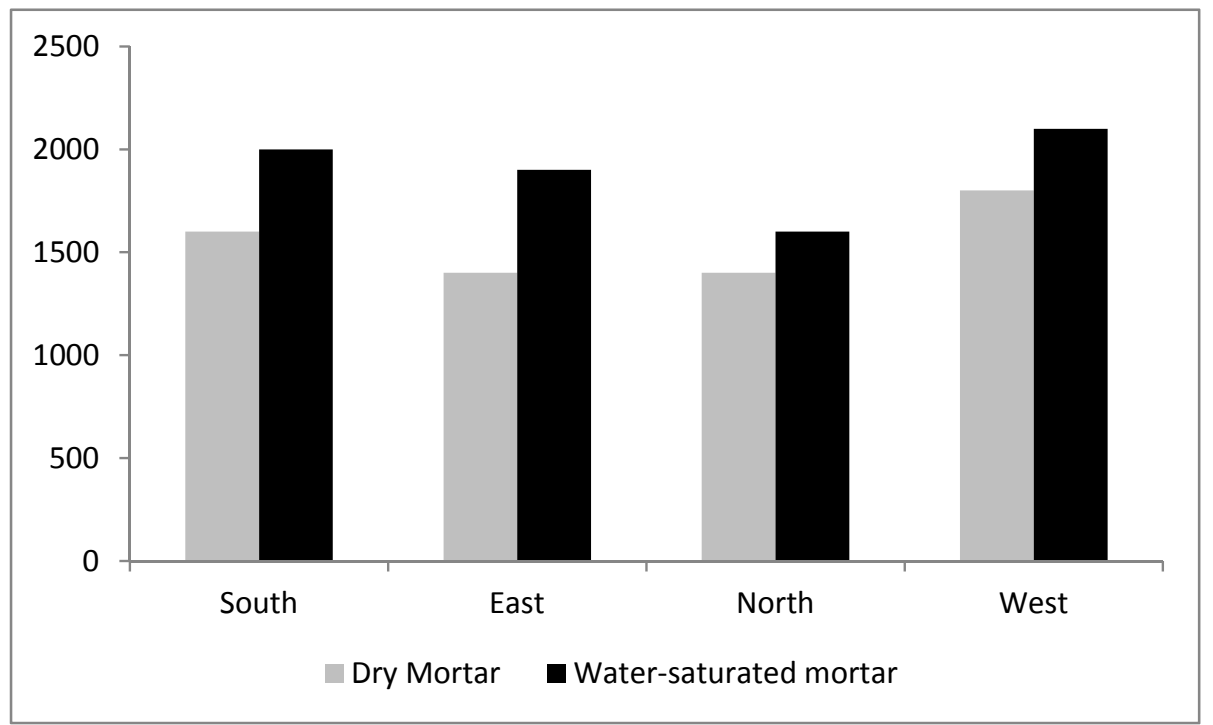

Figure 12. Apparent density $\left(\mathrm{kg} \cdot \mathrm{m}^{-3}\right)$ of the mortars samples.

\subsection{Reconstitution of Mortar}

Reconstitution of mortar by Teutonico's (1988) [30] method (widely used around the world) is presented in Table 4. Although this strictly applies to mortars with fine or very fine grain size (clay or silt), the granulometric analysis of our samples indicated the presence of a low percentage of fine particles (with equivalent diameter less than $0.297 \mathrm{~mm}$ ), and according to this granulometry, the equivalent diameter of particles smaller than $0.2 \mathrm{~mm}$ may also be fine sand.

Table 4. Mortar's reconstitution.

\begin{tabular}{|c|c|c|c|c|c|c|c|c|}
\hline Sample & $\begin{array}{c}\text { Silt and Clay } \\
\text { (\% Fines) }\end{array}$ & $\begin{array}{c}\text { Sand } \\
(\% \text { Thick) }\end{array}$ & $\begin{array}{c}\text { Fines }+ \\
\text { Thick (\%) }\end{array}$ & $\begin{array}{l}\text { Binder } \\
(\%)\end{array}$ & $\begin{array}{c}\text { Fines/ } \\
\text { Binder (\%) }\end{array}$ & $\begin{array}{c}\text { Thick/ } \\
\text { Binder (\%) }\end{array}$ & $\begin{array}{c}\text { Sand (Fines }+ \\
\text { Thick)/Binder (\%) }\end{array}$ & (Sand:Binder) \\
\hline S-002 & 15.88 & 26.27 & 42.14 & 57.86 & 0.27 & 0.45 & 0.73 & $1: 1$ \\
\hline S-004 & 10.37 & 55.83 & 66.21 & 33.79 & 0.31 & 1.65 & 1.96 & $2: 1$ \\
\hline S-005 & 4.40 & 73.20 & 77.60 & 22.40 & 0.20 & 3.27 & 3.46 & $3: 1$ \\
\hline S-006 & 8.12 & 70.42 & 78.53 & 21.47 & 0.38 & 3.28 & 3.66 & $4: 1$ \\
\hline S-008 & 9.11 & 67.21 & 76.32 & 23.68 & 0.38 & 2.84 & 3.22 & $3: 1$ \\
\hline S-009 & 6.85 & 67.56 & 74.40 & 25.60 & 0.27 & 2.64 & 2.91 & $3: 1$ \\
\hline
\end{tabular}

A comparison between the results obtained in the reconstitution of the mortar using different approaches (WDXRF and XRPD analysis on one side and Teutonico's (1988) [30] method on the other) is reported in Table 5. It is possible to verify that the results obtained by WDXRF and XRPD techniques the Teutonico method, indicating that they are suitable tools for the reconstitution of mortars.

Table 5. Comparison of different methods for the reconstitution of mortars.

\begin{tabular}{cccc}
\hline & \multicolumn{3}{c}{ Method } \\
\cline { 2 - 4 } Sample & XRPD & WDXRF & [30] \\
\cline { 2 - 4 } & Quartz:Calcite & SiO $_{2}:$ CaCO $_{3}$ & (Fines + Thick):Binder \\
\cline { 2 - 4 } S-002 & $1: 1$ & $1: 1$ & $1: 1$ \\
S-004 & $2: 1$ & $2: 1$ & $2: 1$ \\
S-005 & $1: 5$ & $1: 4$ & $1: 4$ \\
S-006 & $5: 1$ & $4: 1$ & $4: 1$ \\
S-008 & $3: 1$ & $3: 1$ & $3: 1$ \\
S-009 & $4: 1$ & $3: 1$ & $3: 1$ \\
\hline
\end{tabular}




\subsection{Thermogravimetric Analyses}

In addition to curves with a heating rate of $40^{\circ} \mathrm{C} / \mathrm{min}$, a more detailed study was done using sample S-004 using the rate of $10{ }^{\circ} \mathrm{C} / \mathrm{min}$. Table 6 shows the results by comparing them.

Table 6. Loss of mass of sample S-004 as a function of temperature variation.

\begin{tabular}{ccc}
\hline Temperature Range & Weight Loss (\%) Heating Rate $\mathbf{4 0}{ }^{\circ} \mathrm{C} / \mathbf{m i n}$ & Weight Loss $(\%)$ Heating Rate $\mathbf{1 0}{ }^{\circ} \mathbf{C} / \mathbf{m i n}$ \\
\hline $25-120{ }^{\circ} \mathrm{C}$ & 1.0 & 1.12 \\
$120-200{ }^{\circ} \mathrm{C}$ & 1.0 & 0.62 \\
$200-600{ }^{\circ} \mathrm{C}$ & 3.0 & 3.91 \\
$>600{ }^{\circ} \mathrm{C}$ & 12.0 & 12.25 \\
Total loss & 17.0 & 17.90 \\
\hline
\end{tabular}

Even using a degradation rate considered high for this type of sample $\left(40^{\circ} \mathrm{C} / \mathrm{min}\right)$, it is observed that the results are similar (same order of magnitude) to those obtained at a rate of $10{ }^{\circ} \mathrm{C} / \mathrm{min}$.

The loss of mass up to $120^{\circ} \mathrm{C}$ is directly related to the removal of adsorbed water, predominantly due to the presence of hydraulic binders, in which hygroscopic phases form during the setting and hardening processes; the loss of water in the temperature range $120-200{ }^{\circ} \mathrm{C}$ may be attributed to water of crystallization of hydrated salts, for example gypsum The loss of mass in the temperature range of 200-600 ${ }^{\circ} \mathrm{C}$ can be fully attributed to water chemically bound to aqueous phases (CSH), given that no other hydrated substances decomposing in this temperature range, such as calcium, magnesium hydroxide, layered silicates, etc., were found. The mass loss above $600{ }^{\circ} \mathrm{C}$ is essentially due to the decomposition of carbonates [18].

The highest mass loss (sample S-004) may be attributed to the decomposition of carbonates, in accordance with LOI contents (Figures 13 and 14).

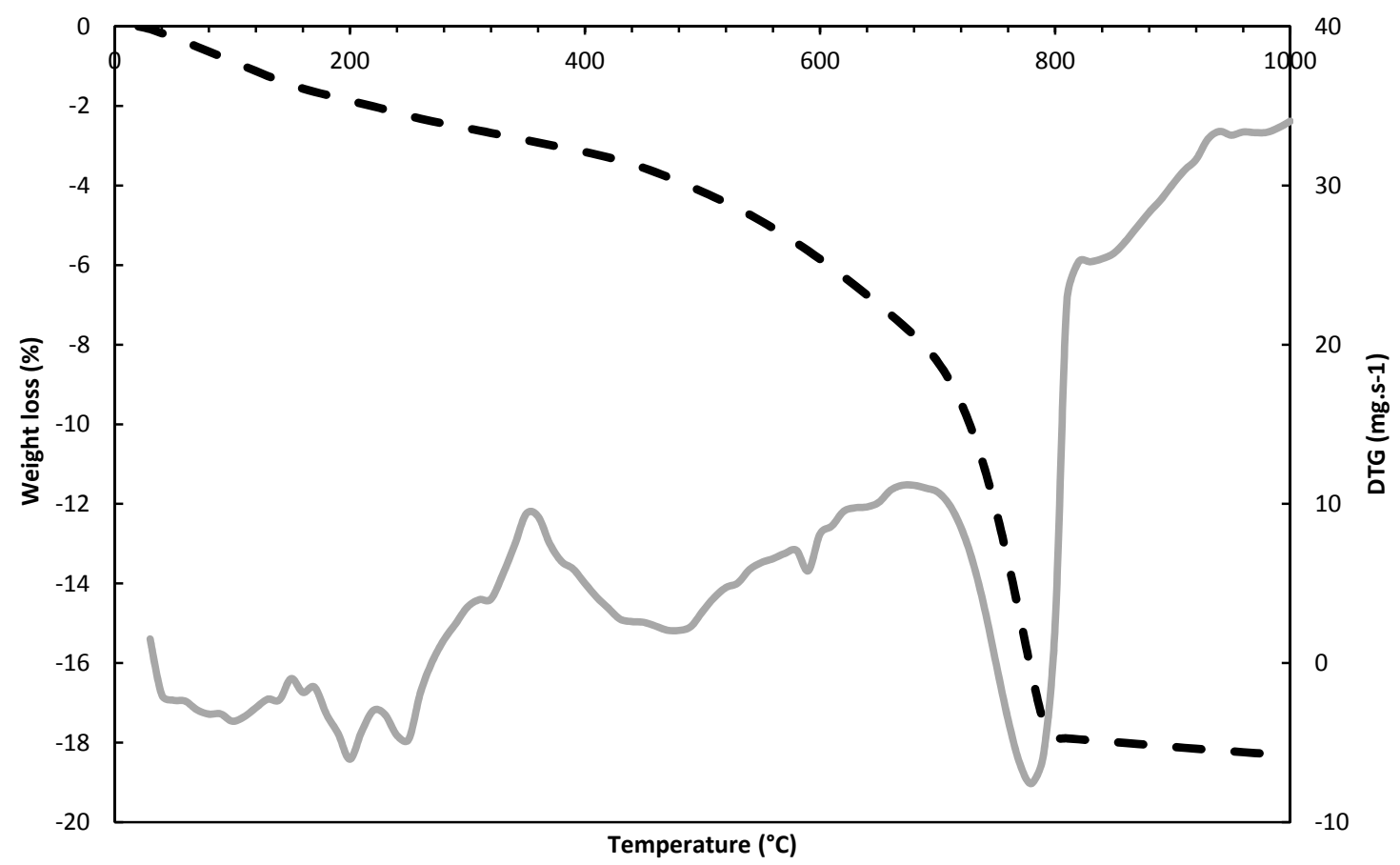

Figure 13. Thermal degradation curve of sample S- 004 with heating rate $10{ }^{\circ} \mathrm{C} / \mathrm{min}$. 


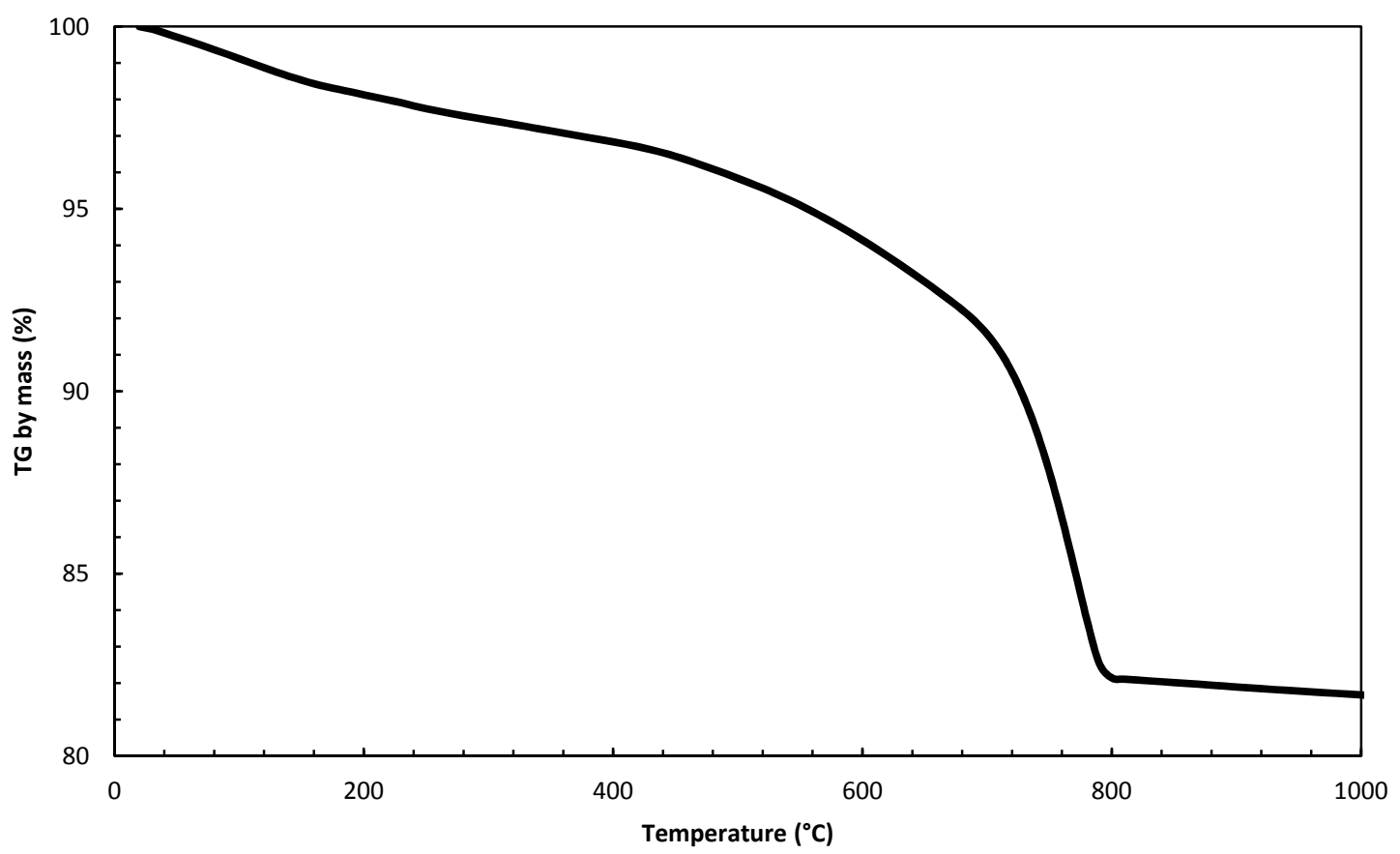

Figure 14. Thermal degradation curve showing the losses in each step with a rate of $10{ }^{\circ} \mathrm{C} / \mathrm{min}$ (sample S-004).

\subsection{Pollution in the Mortars Surfaces}

The results of the chemical analysis of cleaning waters (used for points A, B and C of the facade: see the chapter on methods) are presented in Table 7. In general, the results indicate the level of pollution and alteration of the evaluated material. Samples $B$ and $C$ presented very similar values for most ions. Sulfur $\left(\mathrm{S}^{2-}\right)$ contents $\left(60\right.$ and $50 \mathrm{mg} \cdot \mathrm{L}^{-1}$ at sites $\mathrm{A}$ and $\mathrm{C}$, respectively) and sulfate $\left(\mathrm{SO}_{4}\right)^{2-}$ (about 500 and $400 \mathrm{mg} \cdot \mathrm{L}^{-1}$, sites $\mathrm{A}$ and $\mathrm{C}$, respectively) are indicative of the atmospheric pollution to which the façades are subject, aggravated by the gases emitted by vehicles moving along the nearby São Clemente St., a very important (and busy) way of connection between the south zone and the city center. The high sulphates and calcium contents may be ascribed to the solubilization of gypsum formed over the mortar's surfaces, thus indicating a serious alteration of the façades.

Nitrates, with values around $15 \mathrm{mg} \cdot \mathrm{L}^{-1}$ in samples $A$ and $B$ and $50 \mathrm{mg} \cdot \mathrm{L}^{-1}$ in sample $C$ may be related to air pollution and to the excrement of animals, especially birds.

Table 7. Chemical analysis $\left(\mathrm{mg} \cdot \mathrm{L}^{-1}\right)$ of the washing waters.

\begin{tabular}{cccc}
\hline Ions & AL-A & AL-B & AL-C \\
\hline $\mathrm{Na}^{+}$ & 6.40 & 42.30 & 28.70 \\
$\mathrm{Al}^{3+}$ & $<0.04$ & $<0.04$ & $<0.04$ \\
$\mathrm{Ca}^{2+}$ & 90.40 & 186.00 & 178.00 \\
$\mathrm{Cl}^{-}$ & 2.50 & $<0.02$ & 68.00 \\
$\mathrm{~K}^{+}$ & 5.40 & 13.50 & 11.30 \\
$\mathrm{Fe}^{3+}$ & $<0.06$ & 0.30 & $<0.06$ \\
$\mathrm{Mg}^{2+}$ & 1.30 & 13.60 & 8.20 \\
$\mathrm{~S}^{2-}$ & 1.90 & 58.90 & 51.40 \\
$\left(\mathrm{SO}_{4}\right)^{2-}$ & 525.00 & 32.00 & 397.00 \\
$\left(\mathrm{NO}_{3}\right)^{-}$ & 15.00 & 18.00 & 52.00 \\
\hline
\end{tabular}




\section{Conclusions}

Mortars are extremely complex materials, and a lot of recipes of ancient mortars are present. In this research, the mortars from the facade of the Rui Barbosa House Museum (Rio de Janeiro, Brazil) were analyzed. The chemical composition of the analyzed mortars shows a high percentage of silica (greater than $50 \mathrm{wt} \%$ ). In addition to dominant quartz and calcite, phyllosilicates (kaolinite and muscovite) and K-feldspars (microcline) are present in smaller amounts. Furthermore, traces of albite were found in most of the samples analyzed. Organic compounds and hydrate salts were not detected. It was possible to determine, by the naked eye, the presence of wood fragments and shell pieces, which were seen under the microscope as well. The results indicate that these are mainly lime mortars, and that neither gypsum nor cement was used as binder; in fact, no traces of gypsum, ettringite, or portlandite were detected by X-ray diffraction analysis.

Two samples (S-002 and S-005) present different features with respect to the other mortars: the first is the only sample consisting of pozzolanic material and lime, while the second is the only one that contains very abundant dolomite, which makes this mortar more adhesive than all the others. These two samples have been taken from building corners, which may be easily damaged by people passing by. Therefore, these portions of the façade are not original and probably underwent frequent repairs. The differences in the mortars' chemical, mineralogical and physical features may indicate that, during repairs, no attention was paid to reproduce the original mortars of the façade.

We also suggest that the XRPD and WDXRF techniques are capable of determining the reconstitution of mortar with precision in a shorter time than with the method proposed by Teutonico (1988) [30].

The results related to the effects of pollutants indicate that the building is affected significantly by the action of the sulfur emanated by the vehicles that circulate around it and by the action of the saline spray, since the location of the building is at a small distance (less than $2 \mathrm{~km}$ ) from the sea.

Acknowledgments: The authors acknowledge the Centre of Mineral Technology (CETEM), CETEM researcher Reiner Neumann, National Historic and Artistic Heritage Institute (IPHAN), and the House Museum of Rui Barbosa, Retrofit Company and its employees. This research is financially supported by the Brazilian National Council for Scientific and Technological Development (CNPq).

Author Contributions: R.C.C.R., D.P.S.D. and L.C.R.M. conceived and designed the experiments; L.C.R.M. performed the petrographic analysis; R.C.C.R and D.P.S.D. analyzed the data and wrote the paper.

Conflicts of Interest: The authors declare no conflict of interest.

\section{References}

1. Chiari, G.; Santarelli, M.; Toracca, G. Caraterizzazione delle malte antiche mediante l'analisi di campioni non frazionati. Mater. Struct. 1992, 1, 111-137.

2. Como, M. Statics of Historic Masonry Constructions; Springer: Berlin/Heidelberg, Germany, 2013.

3. Bertolini, L.; Carsana, M.; Gastaldi, M.; Lollini, F.; Redaelli, E. Binder characterization of mortars used at different ages in the San Lorenzo church in Milan. Mater. Charact. 2013, 80, 9-20. [CrossRef]

4. Chiarelli, N.; Miriello, D.; Bianchi, G.; Fichera, G.; Giamello, M.; Memmi, I.T. Characterization of ancient mortars from the S. Niccoló archaeological complex in Montieri (Tuscany Italy). Constr. Build. Mater. 2015, 96, 442-460. [CrossRef]

5. Gleize, P.; Motta, E.; Silva, D.; Roman, H. Characterization of historical mortars from Santa Catarina (Brazil). Cem. Concr. Compos. 2009, 31, 342-346. [CrossRef]

6. Maria, S. Methods for porosity measurement in lime-based mortars. Constr. Build. Mater. 2010, 24, $2572-2578$. [CrossRef]

7. Santiago, C.C. O Restauro de Argamassa de cal no Brasil; Construindo: Belo Horizonte, Brazil, 2012.

8. Bakolas, A.; Biscontin, G.; Moropoulou, A.; Zendri, E. Characterization of structural byzantine mortars by thermogravimetric analysis. Thermochim. Acta 1998, 321, 151-160. [CrossRef]

9. Moropoulou, A.; Bakolas, A.; Bisbikou, K. Characterization of ancient, byzantine and later historic mortars by thermal and X-ray diffraction techniques. Thermochim. Acta 1995, 269, 779-795. [CrossRef] 
10. Moropoulou, A.; Bakolas, A.; Bisbikou, K. Investigation of the technology of historic mortars. J. Cult. Herit. 2000, 1, 45-58. [CrossRef]

11. Biscontin, G.; Birelli, M.P.; Zendri, E. Characterization of binders employed in the manufacture of Venetian historical mortars. J. Cult. Herit. 2002, 3, 31-37. [CrossRef]

12. Freidin, C.; Meir, I. Byzantine mortars of the Negev Desert. Constr. Build. Mater. 2005, 19, 19-23. [CrossRef]

13. Zeng, Y.; Zhang, B.; Liang, X. A case study and mechanism investigation of typical mortars used on ancient architecture in China. Thermochim. Acta 2008, 473, 1-6. [CrossRef]

14. Adriano, P.; Silva, A.S.; Veiga, R.; Mirao, J.; Candeias, A. Microscopic characterisation of old mortars from the Santa Maria Church in Évora. Mater. Charact. 2009, 60, 610-620. [CrossRef]

15. Budak, M.; Akkurt, S.; Bke, H. Evaluation of heat treated clay for potential use in intervention mortars. Appl. Clay Sci. 2010, 49, 414-419. [CrossRef]

16. Sanjurjo-S_anchez, J.; Trindade, M.; Blanco-Rotea, R.; Garcia, R.B.; Mosquera, D.F.; Burbidge, C.; Prudêncio, M.; Dias, M. Chemical and mineralogical characterization of historic mortars from the Santa Eulalia de Bóveda temple, NW Spain. J. Archaeol. Sci. 2010, 37, 2346-2351. [CrossRef]

17. Martínez, I.; Castillo, A.; Martínez, E.; Castellote, M. Physico-chemical material characterization of historic unreinforced masonry buildings: The first step for a suitable intervention. Constr. Build. Mater. 2013, 40, 352-360. [CrossRef]

18. Lezzerini, M.; Legnaioli, S.; Lorenzetti, G.; Palleschi, V.; Tamponi, M. Characterization of historical mortars from the bell tower of St. Nicholas Church (Pisa, Italy). Constr. Build. Mater. 2014, 69, 203-212. [CrossRef]

19. Leone, G.; Vita, A.D.; Magnani, A.; Rossi, C. Characterization of archaeological mortars from Herculaneum. Thermochim. Acta 2016, 624, 86-94. [CrossRef]

20. Moropoulou, A.; Polikreti, K.; Bakolas, A.; Michailidis, P. Correlation of physicochemical and mechanical properties of historical mortars and classification by multivariate statistics. Cem. Concr. Res. 2003, 33, 891-898. [CrossRef]

21. Da Cultura, M. Fundação Casa Rui Barbosa. 2016. Available online: www.casaruibarbosa.gov.br (accessed on 5 June 2016).

22. NPArq, Núcleo de Preservação Arquitetônica, Centro de Memória e Informação, Caderno de Apoio a Elaboração do Caderno de Encargos: Conservação das Superfícies Arquitetônicas do Museu Casa de Rui Barbosa; Tech. Rep.; IPHAN: Rio de Janeiro, Brasil, 2015.

23. Walentaa, G.; Füllmannb, T. Advances in quantitative XRD analysis for clinker, cements, and cementitious additions. Powder Diffr. 2004, 19, 40-44. [CrossRef]

24. Genestar, C.; Pons, C.; Más, A. Analytical characterization of ancient mortars from the archaeological Roman city of Pollentia (Balearic Islands, Spain). Anal. Chim. Acta 2006, 557, 373-379. [CrossRef]

25. Rodrigues, P.N. Caracterização das Argamassas Históricas da Ruína de São Miguel Arcanjo/RS. Master's Thesis, Universidade Federal de Santa Maria, Santa Maria, Brazil, 2013.

26. Saikia, B.J.; Parthasarathy, G. Fourier Transform Infrared Spectroscopic Characterization of Kaolinite from Assam and Meghalaya, Northeastern India. J. Mod. Phys. 2010, 1, 206-210. [CrossRef]

27. Sivakumar, S.; Ravisankar, R.; Raghu, Y.; Chandrasekaran, A.; Chandramohan, J. FTIR Spectroscopic Studies on Coastal Sediment Samples from Cuddalore District, Tamilnadu, India. Indian J. Adv. Chem. Sci. 2012, 1, $40-46$.

28. Sivakumar, S.; Ravisankar, R.; Govardhavan, B.; Anand, D.P.; Jebakumar, J.P.P. Mineral Identification of Coastal Sediment Sample from Karaikal Pondicherry, India by FT-IR Spectroscopic Technique. Sci. Acta Xaver. 2010, 5, 75-82.

29. Moropoulou, A.; Bakolas, A.; Anagnostopoulou, S. Composite materials in ancient structures. Cem. Concr. Compos. 2005, 27, 295-300. [CrossRef]

30. Teutonico, J.M. A Laboratory Manual for Architectural Conservators; ICCROM: Rome, Italy, 1988.

(C) 2018 by the authors. Licensee MDPI, Basel, Switzerland. This article is an open access article distributed under the terms and conditions of the Creative Commons Attribution (CC BY) license (http:/ / creativecommons.org/licenses/by/4.0/). 